\title{
Non-linear finite element analysis of reinforced concrete members and punching shear strength of HSC slabs
}

\author{
Kernou Nassim ${ }^{1}$, Belakhdar Khalil ${ }^{2}$ and Benyamina Abdelrahmane Bekaddour ${ }^{3}$ \\ ${ }^{1}$ Université Docteur Tahar Moulay Saida, Département de génie civil et hydraulique, Saida, Algérie \\ ${ }^{2}$ Université de Tamanrasset, Département de science et technologie, Algérie \\ ${ }^{3}$ Université Ibnkhaldoun de Tiaret, Département de génie civil, Tiaret, Algérie
}

\begin{abstract}
A rational three-dimensional nonlinear finite element model (NLFEAS) is used for evaluating the behavior of high strength concrete slabs under monotonic transverse load. The non-linear equations of equilibrium have been solved using the incremental-iterative technique based on the modified NewtonRaphson method. The convergence of the solution was controlled by a load convergence criterion. The validity of the theoretical formulations and the program used was verified, through comparison with results obtained using ANSYS program and with available experimental test results. A parametric study was conducted to investigate the effect of different parameters on the behavior of slabs which was evaluated in terms of loaddeflection characteristics, concrete and steel stresses and strains, and failure mechanisms. Also, punching shear resistance of slabs was numerically evaluated and compared with the prediction specified by some design codes.
\end{abstract}

\section{Introduction}

Reinforced concrete structures present significant nonlinear and accordingly complex behavior and consequently nonlinear analysis of this kind of structure has been subject of research for many years [2]. In the last decades very sophisticated and accurate structural models were proposed, that can take into account most aspects of the nonlinear behavior of concrete structures $[7,9]$.

The complex behavior of concrete slabs under real conditions leads to strong uncertainties related to material properties of slabs and the loading conditions. These uncertainties must be taken into account to be included in the design guidelines of such structures especially when some structure does not fit exactly in any standard due to its size, new material properties, complexity or multidisciplinary nature. In these cases probabilistic analysis can be pursued since design standards are not able to cover the full range of application that engineers are able to conceive.

Most research on the punching shear strength of slabs has been concerned with the generation of experimental data on simply supported slabs and the development of empirical equations. A few analytical analyses have also been proposed by various investigators based on different models. The most known empirical formula for predicting the shear strength of slabs as result of experimental and analytical studies are those suggested by the ACI-318 code approach.

However, In order to ensure the serviceability requirement of slabs it is necessary to predict the cracking and the deflections of slab structures under service loads. In order to assess the margin of safety of slab structures against failure an accurate estimation of the ultimate load is also essential, in addition to the prediction of the load-deformation behavior of the slab throughout the range of elastic and inelastic response is desirable. The main objectives of this research are: 1-To calibrate and validate the program by comparing the predicted results with available experimental tests and other known software-programs. 2-To study Punching shear behavior and the major material and geometrical parameters that strongly affect it.

\section{Finite Element Formulation}

For the nonlinear analysis of concrete slabs a nonlinear finite element code NLFEAS (Non-Linear Finite Element Analysis of Slabs) has been used. NLFEAS has been developed to predicate and study the behavior of normal and high strength concrete [9]. Its concept and modeling characteristics are described in the following section.

\subsection{Modeling of concrete material in compression}


The behavior of concrete in compression is simulated by an elasto-plastic work hardening model up to onset of crushing. The plasticity model and its constituent, and the modeling of concrete under triaxial state of stress, will be discussed in terms of the following elements: 1) Uniaxial stress-strain relationship, 2) Failure criterion, and 3) Crushing condition.

\subsubsection{Uniaxial stress-strain relationship}

Frequently, the widely used stress-strain relationship of concrete up to the peak stress is given as a parabolic relationship as follows:

$\sigma=f c^{\prime}\left[\frac{2 \varepsilon}{\varepsilon_{0}}-\left(\frac{\varepsilon}{\varepsilon_{0}}\right)^{2}\right]$

Where $\varepsilon_{0}$ is the strain at peak stress $f_{c}$ given by

$\varepsilon_{0}=2 \cdot \frac{f c^{\prime}}{E_{c}}$

In the presence of orthogonal cracks which are caused by shear or transverse tensile stresses, concrete exhibits lower compressive strength and stiffness than uniaxially compressed state. Such degradation or softening in compressive strength of concrete is taken into consideration in the present study by multiplying the uniaxial compressive concrete stress defined in Equation (1) by a softening factor $\lambda$, as shown in Fig. 1. Among various compression reduction models available in literature, the model suggested by Vecchio, and Aspiotis (1994), is implemented in the present finite element formulation. The model can be expressed as:

$$
\lambda=\frac{1}{1+K_{c} \cdot K_{f}}
$$

Where: $K_{c}$, represents the effect of the transverse cracking and straining, $K_{f}$ represents the dependence on the strength of the concrete $\left(f_{c}\right), K_{c}$ and $K_{f}$ are given by:

$$
\begin{aligned}
& K_{c}=0.27\left(\frac{\varepsilon_{r}}{\varepsilon_{0}}-0.37\right) \\
& K_{f}=2.55-0.2629 \sqrt{f c^{\prime}} \leq 1.11
\end{aligned}
$$

Where: $\varepsilon_{r}$ is the tensile strain normal to the cracked plane given by:

For cracked sampling point in the principal direction " 1 " $\varepsilon_{r}=\varepsilon_{1}$

For doubly cracked sampling point in both directions "1"and "2"

$\varepsilon_{r}=\left(\varepsilon_{1}^{2}+\varepsilon_{2}^{2}\right)^{\frac{1}{2}}$

Where $\varepsilon_{l}$ is the transverse tensile strain in the principal direction " 1 " normal to the cracked plane, $\varepsilon_{2}$ is the tensile strain in the second direction " 2 " normal to the second crack plane.

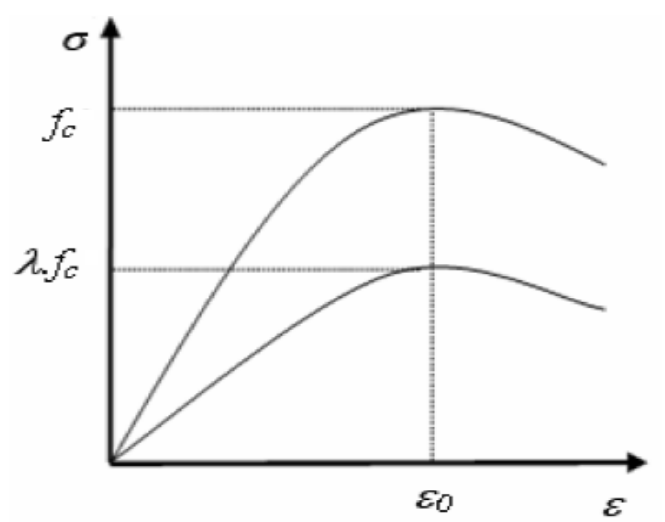

Fig.1. Compression reduction of transversely cracked concrete

\subsubsection{Failure criterion}

Under triaxial state of stress the failure criterion for concrete is generally assumed to be dependent on three stress invariants. However, the failure criterion used in this study is dependent on two stress invariants which has been proved to be adequate for most practical situations and has been successfully used by many investigators for analyzing reinforced concrete plate and shells which can be expressed as:

$$
f(\sigma)=f\left(I_{1}, J_{2}\right)=\sqrt{\alpha I_{1}+3 \beta J_{2}}-\sigma_{0}=0
$$

Where:

$\mathrm{I}_{1}$ is the first stress invariant given by:

$J_{2}$ is the second deviatoric stress invariant

$\sigma_{0}$ is the equivalent effective stress at the onset of plastic deformation,

$\alpha=\sigma_{0}(\beta-1)$

$\beta=\frac{1-2 \cdot \gamma}{\gamma^{2}-2 \cdot \gamma}$

Where, $\gamma$ is a constant to be determined from equal biaxial compression state, which is given by:

$\sigma_{x}=\sigma_{y}=-\gamma \sigma_{0}$

The adopted values of $\gamma$ are taken according to experimental work conducted by Hussein and Marzouk [4]where they found that the constant $\gamma$ has the values of 19,14 and $9 \%$ for concrete strength of $42.7,73.7$ and 96.5 $\mathrm{MPa}$, respectively.

\subsubsection{The crushing condition}

The experimental tests of concrete under multiaxial loading indicate that the crushing is a strain related phenomenon, so concrete is considered to crush when the strain reaches a specified ultimate value, after that the current stresses drop suddenly to zero and the concrete is assumed to lose completely its resistance against further deformation. Hence the crushing criterion is directly obtained by using the same form of yield criterion but in terms of strains, as follow: 
C.I $I_{1}+\sqrt{\left(C_{1} I_{1}\right)^{2}+3 \cdot \beta . J_{2}}=\varepsilon_{c u}$

Where $\varepsilon_{c u}$ the ultimate concrete strain that can be obtained from the uniaxial compression test. Frequently, the ultimate concrete crushing strain $\varepsilon_{c u}$ is estimated to be in the range of 0.0030 as suggested by ACI-318-02 [10] as given by BS8110 [11] and CSA-94 codes [12].

\subsection{Modeling of concrete materials in tension}

When tensile stress exceeds a limiting value a crack is assumed to form in the plane perpendicular to the direction of that stress and concrete behaves no longer isotropic, and therefore, the normal stiffness is reduced through tension-stiffening concept. Once concrete has cracked, fixed smeared cracking model is used in the current study to model the crack. The gradual release of tensile stresses normal to the cracked plane is represented by bilinear average stress-strain curves to simulate the tension stiffening behavior (Fig.2).

The shear stiffness is also reduced when cracking occurs because it retains the two major mechanisms by which shear is transferred across the crack (the aggregate interlock of the rough crack surfaces and dowel action of the reinforcing bars crossing the crack planes). A bilinear shear retention model is used as shown in Fig. 3. The material parameters used in the analysis are as follow:

Tension stiffening: $\alpha_{1}=5, \alpha_{2}=0.6$

Shear retention: $\gamma_{1}=10, \gamma_{2}=0.5, \gamma_{3}=0.04$

Besides, at onset of cracking Poisson's ratio $\left(v_{c}\right)$ is set to

zero.

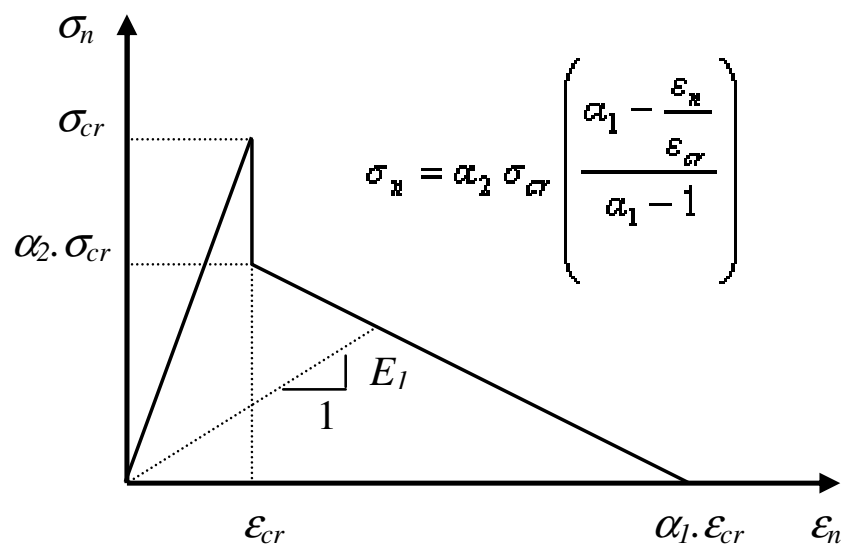

Fig.2. Bilinear average tensile stress-strain of concrete

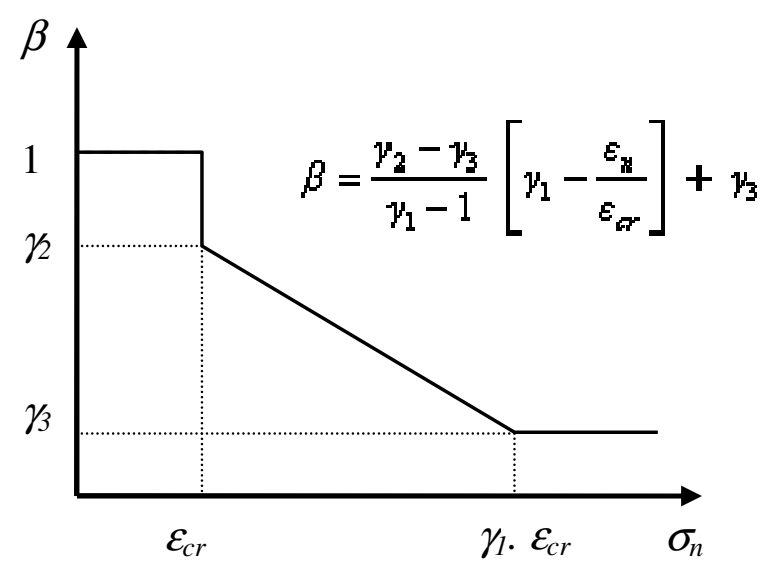

Fig.3. Bilinear shear retention model

\subsection{Material modeling of reinforcement}

In contrast to concrete, the material modeling of steel is rather simple. Frequently, the steel is modeled using linear elastic-full plastic model, as shown in Fig.4.

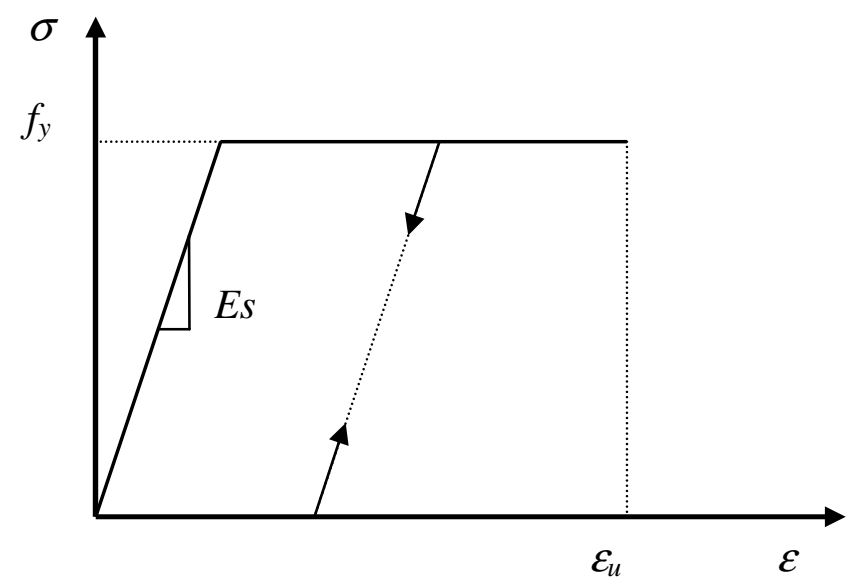

Fig.4. Modeling of steel reinforcing bars

\subsection{Finite element idealization}

The concrete is represented by using 8-noded brick element. The reinforcing bars are modeled as one dimensional element subjected to axial force only. The non-linear equations of equilibrium have been solved using the incremental-iterative technique based on the modified Newton-Raphson method. The convergence of the solution was controlled by a load convergence criterion. NLEFAS program interface as shown in Fig.5. 


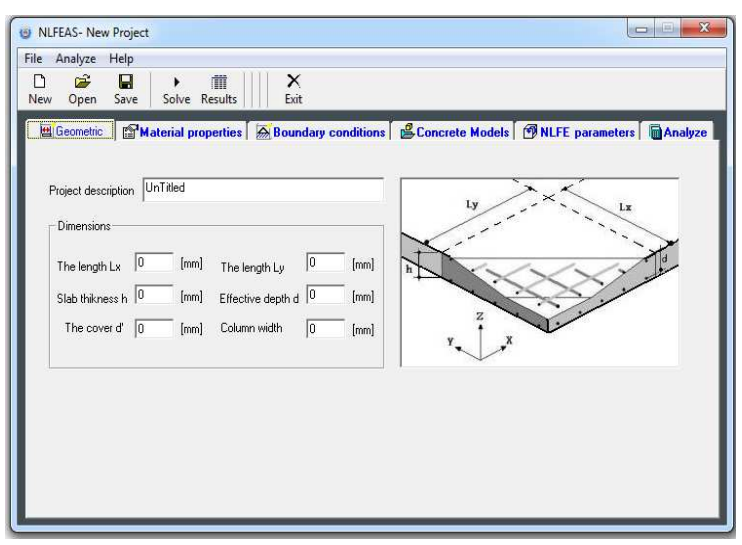

Fig.5. NLEFAS program interface

\section{Description of selected experimental slab}

A simply supported square slabs were selected from an experimental test of reinforced concrete slabs made of HSC, to be used to validate the predicted analytical results and to be used for the reliability analysis. The selected experimental slab was one of eleven slabs carried out by Tmaszewicz [2]. The selected slab was named "ND95-2-3D", it has span of $2200 \mathrm{~mm}$, with thickness of $240 \mathrm{~mm}$. The concrete strength $f_{c}{ }^{\prime}$ was 80.3 $\mathrm{MPa}$ while the steel yielding stress $f_{y}$ was $500 \mathrm{MPa}$. The steel ratio was $2.34 \%$

The following material properties are assumed in the analysis: $E s=200.000 \mathrm{MPa}, E c=3320 \cdot \sqrt{f_{c}{ }^{\prime}}+6900$,

$f_{t}=0.33 \sqrt{f_{c}{ }^{\prime}}$, and $v_{\mathrm{c}}=0.24$.

\section{Finite element mesh}

The concrete is represented by using 8-noded brick element. The reinforcing bars are modeled as one dimensional element subjected to axial force only, and perfect bond is assumed to occur between the two materials,

By taking advantage of symmetry, a segment representing one quarter of the slabs has been considered in the finite element analysis, noting that the slab was modeled upside down and the loading is applied on the column as shown in Fig.6.

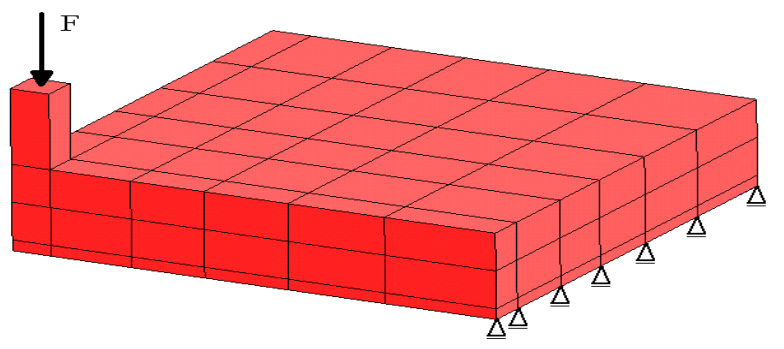

Fig.6. Finite element mesh

\section{Validation of the NLFEM program}

The results of the present nonlinear finite element analysis of the investigated slabs in terms of ultimate load are compared against the experimental measurements and listed in Table 1. Fig. 6 shows loaddeflection curves of selected slabs of the present finite element analysis and experimental results. According to Fig 6 and Table 1, it can be observed that the present finite element model performs satisfactory and it predicts accurately the real behavior of slabs.

Table 1. Comparison of the predicted and experimental results

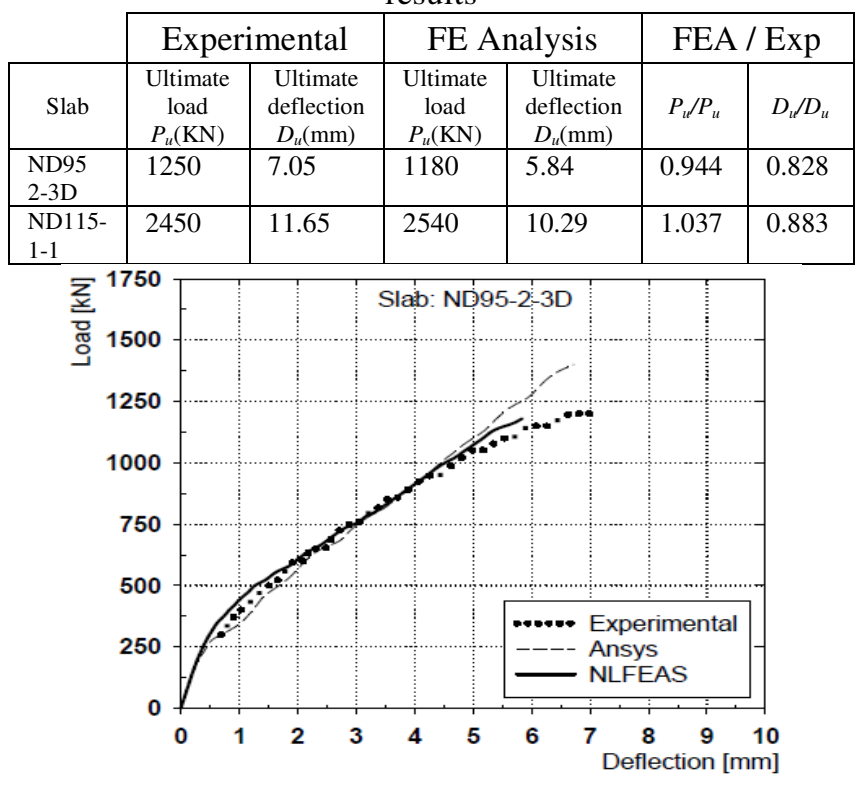

Fig.6. Comparison of predicted and experimental loaddeflection curves.

\subsection{Effect of compressive strength grade}

The concrete compressive strength considered as one of the important primary variables that was studied in the present investigation. The influence of $f c^{\prime}$ on the selected slabs' behavior was studied through altering the values of $f c$ ' by different values, and the obtained results are illustrated in Fig.8. It can be seen that generally, the higher the value of $f c^{\prime}$, the higher the expected stiffness and the ultimate load of any slab. It was stated previously that increasing the value of $f c$ ' influences the loaddeflection behavior particularly after cracking, but the shape of the load-deflection curve was not highly influenced. 


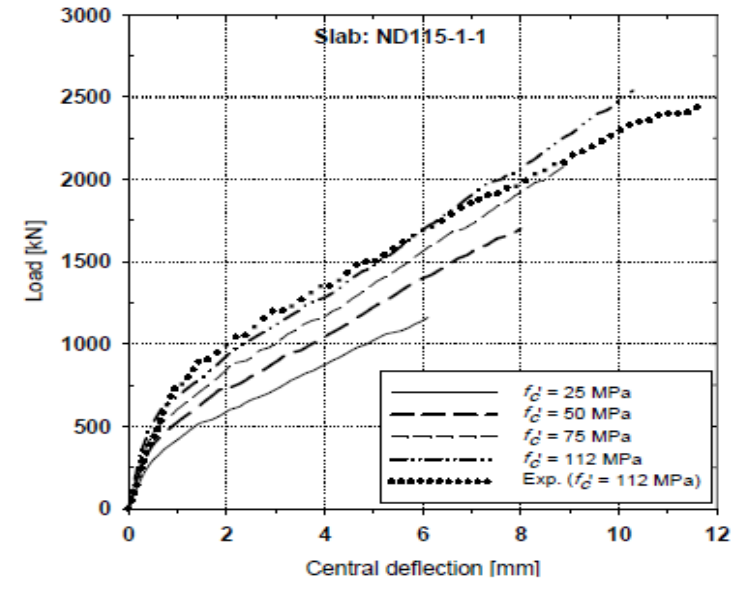

Fig.8. Effect of compressive strength $f c^{\prime}$ on the slab response

\subsection{Comparison of the experimental punching strength versus present prediction and codes predictions}

Experimental results were used to check the validity of the punching shear strength formula given in AS3600 [1], CEB-FIP [3] and NLFEAS [9]. Marzouk and Hussein [4] tested 17 square specimens to investigate the punching shear behaviour of high-strength concrete slabs. Tomaszewicz [2] tested 19 square flat slabs with orthogonal, equally spaced flexural reinforcement and without shear reinforcement. A total of 29 test results from four research studies conducted by Ramdane [8], Hallgren and Kinnunen [6], Marzouk and Hussein [4] and Tomaszewicz [2], were compared to values of punching strength calculated using AS3600. the punching shear strength values specified in different codes vary with concrete compressive strength $f_{c}^{\prime}$ and is usually expressed in terms of $f_{c}^{n}$. In AS3600 (Cl. 9.2.3) the punching shear strength is expressed as proportional to $\sqrt{f_{c}^{\prime}}$. The ultimate shear strength for slabs without prestress is given by $V_{u o}=u d\left(f_{c v}\right)$ where: $u=$ length of the critical perimeter.

$$
\begin{aligned}
& f_{c v}=\text { punching shear strength } \\
& f_{c v}=0.17\left(1+\frac{2}{\beta_{h}}\right) \sqrt{f_{c}^{\prime}} \leq 0.34 \sqrt{f_{c}^{\prime}}
\end{aligned}
$$

$\beta_{\eta}$ : ratio of longest column dimension to shorter column dimension

In CEB-FIP the punching shear resistance, $F_{s d}$ is expressed as proportional to $\left(f_{c k}\right)^{\frac{1}{3}}$, Where $f_{c k}$ is the characteristic compressive strength of concrete. The highest concrete grade considered in CEB-FIP, which corresponds to $f_{c k}$ equal to $80 \mathrm{MPa}$. For the calculation of punching load capacity.

$$
F_{s d}=0.18 \xi\left(100 \rho f_{c k}\right)^{\frac{1}{3}} u_{1} d
$$

In this study, measured concrete strength is taken as $f_{c k}$. Fig.9 shows the ratios between test results and the failure loads predicted by different formulae plotted with respect to the concrete strength. The experimental ultimate loads $\left(\mathrm{P}_{\text {test }}\right)$ of the slabs to the values predicted by AS3600 and
CEB-FIP is compared. two points from AS3600 fall below the safety margin with one result for a slab with a concrete strength of $112 \mathrm{MPa}$. The AS3600 formula can be considered to be applicable up to $100 \mathrm{MPa}$. However the ratios between observed and calculated loads clearly show that AS3600 is less conservative for the HSC slabs and high scatter is found. Therefore, all above codes and present FE model may be considered applicable for predicting the punching strength of HSC up to $118 \mathrm{MPa}$.

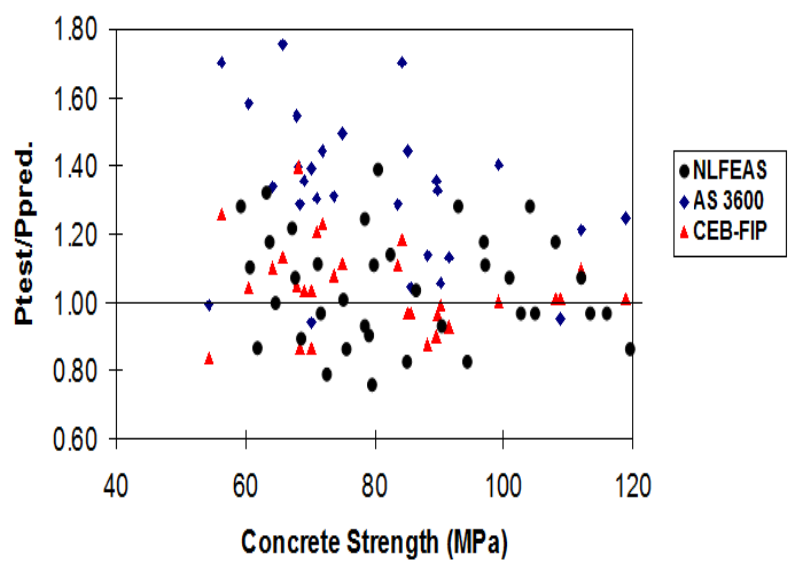

Fig.9. Ratios of experimental and predicted shear strengths

\section{Conclusion}

The main conclusion extracted from the current study is that the nonlinear finite element method based on advanced 3D models is a powerful and relatively economical tool which can be effectively used to simulate the true behavior of reinforced concrete even under complicated conditions.

The presented finite element program (NLFEAS) is used for the analysis of high strength reinforced concrete slabs subjected to monotonic concentrated loads after calibration using many experimental data. Predictions of the present FE program are compared with valuable experimental data, and the comparisons were judged good. Moreover, the model was able to predict the total response and capacity of the high strength concrete slabs and to indicate the type of failure (flexural or shear).

In AS3600 the punching shear strength is expressed as proportional to $\sqrt{f_{c}^{\prime}}$. However in CEB-FIP punching shear strength is assumed to be proportional to $\sqrt[3]{f_{c}^{\prime}}$.

The comparison of experimental results show that the AS3600 formula is applicable up to $100 \mathrm{MPa}$. However the ratios between observed and calculated loads clearly show that AS3600 is less conservative for the HSC slabs. The code of CEB-FIP formula is less conservative for HSC slabs and may be unsafe for some cases.

\section{References}


1. AS3600: Concrete Structures Standard. Standards Association of Australia, (1994).

2. A. Tomaszewicz. High-strength Concrete SP2 - Plates and Shells. Report 2.3, Punching Shear Capacity of Reinforced Concrete Slabs. Report No. STF70A93082, SINTEF, Trondheim, (1993).

3. CEB-FIP State-of-the-art report on high-strength concrete. 90/1/1, Bulletin d'Information No. 197, (1990).

4. H.Marzouk, A.Hussein. Experimental Investigation on the Behavior of High Strength Concrete Slabs. ACI structural journal November-December 1991; 88(6) 701-513;(1991).

5. H.Marzouk ,Z. Chen, Z. "Finite Element Analysis of High Strength Concrete Slabs," ACI Structural Journal, V. 90, No. 5, September-October 1993, pp. 505-513; (1993).

6. M.Hallgren, and S.Kinnunen,. Increase of Punching Shear Capacity by using High-Strength Concrete. 4th International Symposium on Utilization of Highstrength/High-performance Concrete. Paris, 1996, pp. 1037-1046;(1996).

7. N.Kernou, B.Youcef, K. Belakhdar, K. . Assessment of reliability and punching shear resistance of slabs, GRAĐEVINAR, 67 (11), 1051-1062, (2015) doi: https://doi.org/10.14256/JCE.1295.2015.

8. K.E.Ramdane, Punching Shear of High Performance Concrete Slabs. 4th International Symposium on Utilization of High-strength/High-performance Concrete. Paris, 1996, pp. 1015-1026; (1996).

9. M. M. Smadi and K. A. Belakhdar, "Nonlinear finite element analysis of high strength concrete slabs", Computers and Concrete, Vol. 4, No. 3, pp 187-206, (2007).

10. ACI 318-2002. Building Code Requirements for Structural Concrete (ACI 318-02) and Commentary (2002).

11. BS-8110. Structural Use of Concrete, Part 1:Code Practice For Design and Construction,. British Standards Institution, Londan (1985).

12. CSA, Design of concrete structures for buildings, Standard A23.3- 94, Canadian Standards Association, Rexdale, Ontario,( 2004). 